\title{
ATTENTION AND COGNITION
}

\section{PRENATAL MARIHUANA, CIGARETTES, ALCOHOL AND ATTENTIONAL BEHAVIOR}

A follow-up study of intentional behavior in 6 year old children exposed prenatally to marihuana, cigarettes and alcohol is reported from the Department of Psychology, Carleton University, Ottawa, Ontario, Canada. Discriminant function analysis in 126 children revealed a dose response association between prenatal cigarette exposure and impulsive behavior. Performance on memory tasks requiring verbal recall was negatively associated with maternal cigarette use. Prenatal marihuana was associated with omission errors in vigilance tasks reflecting a deficit in sustained attention. The mother's rating of impulsive hyperactive behavior was also higher. Low levels of maternal alcohol consumption were related to decreased impulsive responding, assessed by mothers' reports by mothers reports (Fried PA et al. A follow-up study of attentional behavior in 6-year-old children exposed prenatally to marihuana, cigarettes, and alcohol. Neurotoxicol Teratol Sept/Oct 1992; 14:299-311). (Reprints: Dr. Peter A. Fried, Department of Psychology, Carlton University, Ottawa, Ontario, Canada K1S 5B6.)

COMMENT. No negative relationship between prenatal alcohol exposure and attention related variables was noted in this study. The only differences related to maternal alcohol consumption were in decreased impulsivity: fewer responses were made in the delay tasks and a decreased degree of impulsivity/hyperactivity in the child was reported by the mother. Others have reported an increased reaction time associated with maternal alcohol consumption in 4 and 7 year old children on vigilance tasks. The timing of the exposure to the alcohol was not determined in this present study, and relatively low levels of alcohol were consumed by the mothers. This could account for the absence of negative association between attentional behavior and maternal alcohol use.

\section{CONGENITAL DEGENERATIVE DISORDERS}

\section{RETT SYNDROME: GROWTH AND NUTRITION}

Feeding problems, dietary intake and the growth and nutrition of 10 girls with Rett syndrome were reported from the University of Oslo, Norway. All patients had birth weight and length within the normal range until 6 to 24 months of age. A fall off in linear growth occurred in the first 2 years of life, and at follow-up between 3 and 16 years of age, all but 1 had height and/or weight below the 2.5 percentile of healthy children. Oral-motor dysfunctions were common. The mean energy intake was $70 \%$ of the U.S. recommendations according to age and $108 \%$ according to body weight. The intakes of thiamin, vitamin D, calcium and iron were low. None was anemic (Thommessen $M$ et al. Growth and nutrition in 10 girls with Rett syndrome. 
Acta Paediatr Sept 1992; $\underline{81: 686-690) . ~(C o r r e s p o n d e n c e: ~ D r . ~ M . ~ T h o m m e s s e n, ~ O s l o ~}$ City Department of Environmental Health, Saint Olavs plass 5, 0165 Oslo 1, Norway.)

COMMENT. The authors conclude that feeding problems and inadequate intake of nutrients contribute to the poor weight and growth of girls with Rett syndrome. Consultation with a dietician is important in children with Rett syndrome.

Rett syndrome in a pair of full sisters is reported from Sao Paulo, Brazil (Kok F et al. Pediatr Neurol Sept/Oct 1992; $\underline{8}: 381$ (abstract)). The occurrence of familial cases is very rare and up to now, 3 pairs of full sisters, 2 pairs of half sisters, and 1 aunt/niece pair had been reported. All 2 pairs of female dizygotic twins have been discordant and all 8 pairs of monozygotic twins have been concordant for the disease. The parents of the reported sisters with Rett syndrome were unrelated.

\section{ANGELMAN SYNDROME: CHROMOSOME ABNORMALITY}

Clinical cytogenetic and molecular evidence in 1 patient with paternal uniparental disomy (UPD) for chromosome 15 is reported from the University of Florida College of Medicine, Gainesville, FL. The deletions of chromosome 15 q11-q13 were demonstrated with DNA probes. Twenty-seven patients with a clinical diagnosis of Angelman syndrome were evaluated in the laboratory by molecular genetic techniques. Twenty had a molecular deletion of 15 q11-q13, whereas 6 had biparental inheritance for chromosome 15 DNA markers. The 7 th patient, who did not have a molecular deletion, had paternal UPD for chromosome 15. This is the first patient in whom UPD involved the critical chromosomal region. The overall frequency of paternal UPD was calculated at $3.7 \%$. The low frequency of UPD in Angelman syndrome contrasts with the high frequency of $25 \%$ for maternal UPD in Prader-Willi syndrome (Nicholls RD et al. Paternal uniparental disomy of chromosome 15

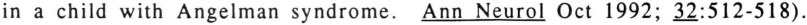
(Correspondence: Dr. Nicholls, Department of Neuroscience, Box 100244 JHMHC, University of Florida College of Medicine, Gainesville, FL 32610.)

COMMENT. Angelman syndrome is characterized by severe mental retardation, absence of speech, inappropriate laughter, puppet-like ataxic movements, microbrachycephaly, seizures, an abnormal electrocephalogram, mild hypotonia, hypopigmentation and prognathism with tongue protrusion. Most cases of Angelman syndrome are due to deletions of exclusively maternal origin from a critical region in chromosome 15 q11-q13. For a review of the diagnostic features of 36 cases of Angelman syndrome see Robb SA et al. Arch Dis Child Jan 1989; 64:83 and Progress in Pediatric Neurology, Millichap JG (ed), Chicago, PNB Publ, 1991, pages 487-88. 